\title{
Effect of Psycho-Educative Intervention on Adherence to Treatment, Knowledge and Attitude among Persons with Bipolar Affective Disorder (BPAD) - Randomized Controlled Trial
}

\author{
Dr. Linu Sara George ${ }^{1}$, Dr. PSVN Sharma ${ }^{2}$, Dr. Sreekumaran Nair ${ }^{3}$ \\ ${ }^{1}$ Manipal College of Nursing, Manipal University, Manipal, India \\ ${ }^{2}$ Department of Psychiatry, Kasturba Hospital, Manipal University, Manipal, India \\ ${ }^{3}$ Department of Statistics, Manipal University, Manipal, India
}

\begin{abstract}
Introduction: Enhancement of treatment adherence in bipolar disorder is a necessary and promising management component as an adjunct to pharmacotherapy. The main purpose of the study was to find the effect of psycho-educative intervention on adherence to treatment among persons with BPAD.

Method: A randomized controlled trial was conducted with a sample size of 50; 24 in experimental and 26 in control group. Four sessions of psycho-education was given to the patient in experimental group and the outcome was measured immediately after the intervention and at 1 month and 3 months.

Results: The study findings shows that there was a significant improvement of knowledge and attitude scores among the experimental group to the control group $(p=0.001)$. There was a difference in adherence seen between the groups, however the difference was not statistically significant $(p=0.111)$.

Conclusion: From the present study it was concluded that psycho educative intervention along with pharmacotherapy is one of the most easy, flexible and cost effective intervention to enhance treatment adherence in bipolar disorder.
\end{abstract}

Keywords:Adherence to treatment, attitude. Bipolar affective disorder, effect, knowledge, psycho-educative intervention.

Trial registration: Clinical Trial Registry India / 2010/091/000476

Accepted Date: 27 .June 2013

\section{Introduction}

Bipolar disorder is a recurrent and long term mental illness that can seriously affect the lives of patients and their families. Globally the lifetime prevalence of all forms of the illness, often referred to as bipolar spectrum disorders, has been estimated to be 5\% in the general population [1,2]. Ganguli (2000) reported that the national rate of affective disorder in India as 34 per 1000 population [3]

Adherence is a crucial determinant of the treatment outcome of any condition. Poor adherence may affect the therapeutic alliance. A study by Berk KL et al (2010) on therapeutic insight and two measures of medication adherence found that $27 \%$ had poor adherence based on missed dose and $46 \%$ had poor adherence based on Morisky medication adherence scale [4].

Centorrino et al 2001 identifiedthe factors that were significantly associated with missing a visit included chronic illness, partial or full remission and major affective disorder [5]. There are multiple indicators of treatment adherence that can be measured using direct and indirect methods, which include pill counts, pharmacy records, smart pill containers and medication plasma level [6].

Enhancement of treatment adherence in bipolar disorder is a necessary and promising management component as an adjunct to pharmacotherapy. The psychosocial interventions that target medication adherence in bipolar disorder point to the possibility of refining the concept of non- adherence and adapting psycho education to the needs of certain subgroups of people with bipolar disorder [2]. Psycho education is aimed at improving knowledge, attitude and adherence behavior.

Pharmacological approaches alone are also often insufficient to achieve a cure for bipolar disorders. Both pharmacological treatments and psychological interventions coincide in their primary goal, namely avoiding recurrence and improving clinical outcome. Psycho-educational goal includes helping patients to adjust and come to terms with a chronic illness, enhancing treatment compliance, providing information and emotional support to patients and their families [7]. 
Psycho-education process involves key members of the person's social network, including spouse, family members and caregivers. Psycho education is a key component of psychosocial interventions. It can take place on an individual basis or as a part of group therapy.

The primary objective of the study was to compare the effect of psycho-educative intervention in improving adherence to treatment among persons with BPAD. The secondary objective was tofind the effect of psycho-educative intervention on persons with BPAD in terms ofincrease in knowledge on BPAD scores and improvement in attitude on BPAD scores.

\subsection{Study population, Study design}

\section{Materials And Methods}

The study was a Randomized controlled trial (RCT) with two group parallel design. Intervention group received psycho educative intervention and control group received routine care. Persons with Bipolar Affective Disorder who were between 20-60 years of age, who could speak and understand Kannada, patients who could listen, comprehend and speak clearly and persons who were having a Young Mania Rating Scale (YMRS) [8] score of less than or equal to 8 or Hamilton Depression Rating Scale (HDRS) [9] score of less than or equal to10 were recruited in trial. Persons who were having chronic medical illness and those who were diagnosed with drug dependence or organic mental disorders were excluded from the study.

The sample size was calculated by considering the adherence to treatment as the primary outcome measure. It was assumed that, the general adherence is $50 \%$ and expecting the change to $75 \%$ after completion of the intervention as clinically significant.The alpha value was taken as 1.282 with a power of $80 \%$ and the level of significance as 5\%.The sample size obtained was 30 in experimental group and 30 in control group from two selected hospitals of Udupi District, Karnataka, India.

Patients were randomly assigned to experimental and control arms by block randomization during the stay in the hospital. The experimental group was given the psycho-education while both the groups were receiving the routine care. The routine care included pharmacotherapy, electro convulsive therapy where indicated and other informal teaching given by the treating doctors. Both the groups were assessed at baseline, immediately after the last session and at one and three months. The baseline assessment was done at the time of discharge. The flow chart showing the subject recruitment is shown in fig.1.

Written permission was obtained from the concerned hospital authorities. Permission was also obtained from the hospital ethics committee.Adequate information was given to the persons with BPAD and caregivers and an informed consent was obtained.

\subsection{Intervention}

Psycho-educative intervention was carried out by the investigator in four sessions with each session lasting for 30 minutes. The intersession interval was one month. The sessions were divided into meaning and causes, signs and symptoms, treatment and ways to lead a healthy life. The psycho educative intervention had to be taken up in the follow up period in the outpatient department as the patient had to achieve substantial remission in symptoms before introducing this intervention. The intervention was delivered using flip charts, posters and handbook on Bipolar Disorder prepared by the investigator. The immediate effect was checked by administering the tools after the completion of the fourth session and short term effect at one month and three months after the intervention.

The participants in the intervention group were given a medicine box with an instruction to keep the tablets in it and medication diary to put a tick mark in the appropriate column as soon as the tablet was taken. They were instructed to bring the empty medicine strips and the filled diary during the follow up to check the number of medicines missed as well as taken. They were encouraged to consume the tablets and informed of the next visit date. Both the caregivers and patients were informed about the medicine box and the diary. The main purpose was to determine the adherence to treatment.

\subsection{Outcome measures}

The primary outcome measure in the study was adherence to treatment. The adherence was checked by counting the tablets when they were prescribed, at the time of follow-up and also checking the diary which was maintained by the participants. The adherence rate was calculated based on the tablets prescribed for a period and the tablets missed by the participant. Adherence to treatment rate was calculated three months after the intervention.

The secondary outcome measures included are Knowledge on Bipolar Affective disorder and Attitude. The tools used were: Socio-demographic Proforma, Knowledge Questionnaire, Attitude scale, Young mania rating scale/ Hamilton depression rating scale according to the diagnosis of the patient. The Socio demographic Proforma was used to collect the background information of the patient. The knowledge questionnaire consisted of 20 structured items under the areas meaning, epidemiology, causes, features, treatment and warning signs. The 
attitudescale consisted of 20 items under the areas; concept, occurrence, cause, treatment, relationship with family, acceptance and stigma.

\subsection{Statistical Analyses}

The statistical package SPSS 16.0 was used for descriptive and inferential statistics. Frequencies and percentage were computed for describing baseline characteristics of persons with Bipolar Affective Disorder. To determine the significant difference in adherence to treatment among persons with Bipolar Affective Disorder in the experimental group as compared to the control group, Fisher Exact test was done. Repeated measure analysis of variance was used to find the effect of psycho educative intervention on knowledge and attitude among persons with Bipolar Affective Disorder.

\section{Results}

Figure 1 shows the flow of subjects recruited to the study.

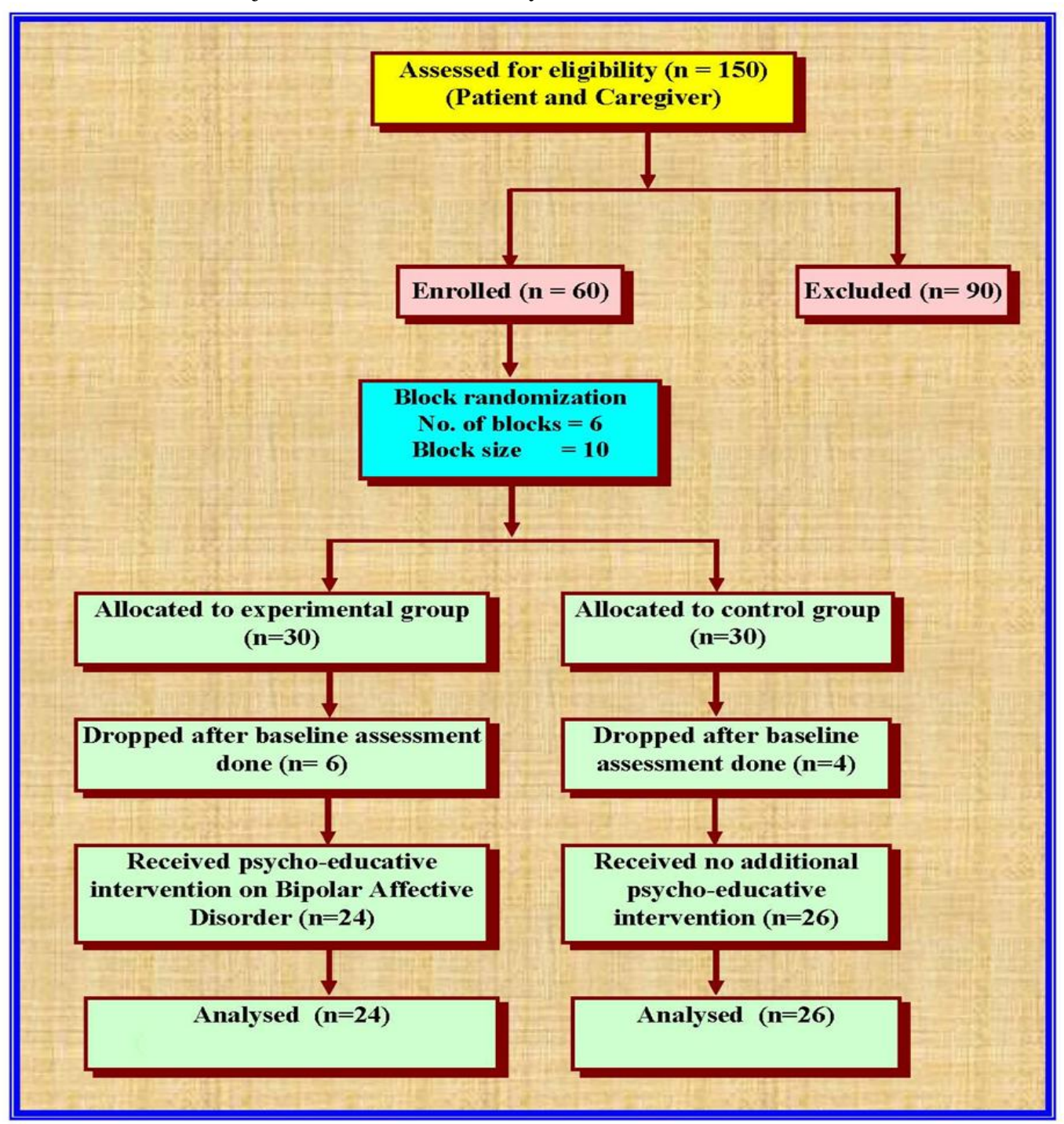

Fig 1: flow chart of subjects recruited to study 
3.1 The baseline characteristics were summarized in table 1. Both the groups were comparable at baseline.

Table 1: Baseline characteristics of trial participants

\begin{tabular}{|c|c|c|c|c|c|c|}
\hline \multirow[t]{2}{*}{ Socio demographic variables } & \multicolumn{2}{|c|}{$\begin{array}{l}\text { Experimental } \\
(\mathrm{n}=24)\end{array}$} & \multicolumn{2}{|c|}{$\begin{array}{l}\text { Control } \\
(\mathbf{n}=26)\end{array}$} & \multicolumn{2}{|c|}{$\begin{array}{l}\text { Total } \\
(\mathbf{n}=50)\end{array}$} \\
\hline & $\mathbf{N}$ & $\%$ & $\mathbf{N}$ & $\%$ & $\mathbf{N}$ & $\%$ \\
\hline \multicolumn{7}{|l|}{ Age in years } \\
\hline $20-40$ & 17 & 70.8 & 18 & 69.2 & 35 & 70 \\
\hline $41-60$ & 7 & 29.2 & 8 & 30.8 & 15 & 30 \\
\hline \multicolumn{7}{|l|}{ Gender } \\
\hline Male & 10 & 41.67 & 10 & 38.46 & 20 & 40 \\
\hline Female & 14 & 58.33 & 16 & 61.54 & 30 & 60 \\
\hline \multicolumn{7}{|l|}{ Education } \\
\hline$<$ PUC & 16 & 66.7 & 18 & 69.2 & 34 & 68 \\
\hline >_PUC & 8 & 33.3 & 6 & 23.1 & 14 & 28 \\
\hline Illiterate & 0 & 0 & 2 & 7.7 & 2 & 4 \\
\hline \multicolumn{7}{|l|}{ Occupation } \\
\hline Agriculture & 1 & 4.2 & 3 & 11.4 & 4 & 8 \\
\hline Coolie & 2 & 8.3 & 6 & 23.1 & 8 & 16 \\
\hline House wife & 10 & 41.7 & 8 & 30.8 & 18 & 36 \\
\hline Clerical & 1 & 4.2 & 0 & 0 & 1 & 2 \\
\hline Teacher & 2 & 8.3 & 1 & 3.9 & 3 & 6 \\
\hline Professional & 0 & 0 & 1 & 3.9 & 1 & 2 \\
\hline Others & 8 & 38.3 & 7 & 26.9 & 15 & 30 \\
\hline \multicolumn{7}{|l|}{ Marital status } \\
\hline Married & 14 & 58.3 & 12 & 46.2 & 25 & 52 \\
\hline Unmarried & 8 & 33.3 & 11 & 42.3 & 19 & 38 \\
\hline Widowed & 1 & 4.2 & 3 & 11.5 & 4 & 8 \\
\hline Divorced /separated & 1 & 4.2 & 0 & 0 & 1 & 2 \\
\hline \multicolumn{7}{|l|}{ Religion } \\
\hline Hindu & 22 & 91.7 & 24 & 92.3 & 46 & 92 \\
\hline Christian & 0 & 0 & 2 & 7.7 & 2 & 4 \\
\hline Muslim & 2 & 8.3 & 0 & 0 & 2 & 4 \\
\hline \multicolumn{7}{|l|}{ Type of family } \\
\hline Nuclear & 13 & 54.2 & 19 & 73.1 & 32 & 64 \\
\hline Joint & 9 & 37.5 & 6 & 23.1 & 15 & 30 \\
\hline Extended & 2 & 8.3 & 1 & 3.9 & 3 & 6 \\
\hline
\end{tabular}

\subsection{Adherence to treatment}

All 24 patients in the experimental group belong to the adherence rate of $75 \%$ and above which shows adherence. In the control group four subjects had less than $75 \%$ adherence. However, this was not statistically significant.

\subsection{Effect of psycho-educative intervention}

Data presented in table 2 show that the average improvement of knowledge score in the experimental group is significantly higher than the control group $(\mathrm{p}=0.001)$. This improvement is retained after 3 months of intervention.

Table 2: Difference in knowledge scores among persons with BPAD

\begin{tabular}{|c|c|c|c|c|c|}
\hline \multirow[b]{2}{*}{ Group } & \multicolumn{4}{|c|}{ Knowledge scores } & \multirow[b]{2}{*}{ p value } \\
\hline & $\begin{array}{l}\text { Post test1- } \\
\text { pretest } \\
\text { Mean } \pm \text { SD } \\
(95 \% \text { CI })\end{array}$ & $\begin{array}{l}\text { Post test 2-pret } \\
\text { Mean } \pm \text { SD } \\
\text { (95\% CI) }\end{array}$ & & $\begin{array}{l}\text { Post test 3-pretest } \\
\text { Mean } \pm \text { SD } \\
(95 \% \text { CI })\end{array}$ & \\
\hline $\begin{array}{l}\text { Experimental } \\
(\mathrm{n}=24)\end{array}$ & $\begin{array}{l}16.9 \pm 10.5 \\
(12.5 \text { to } 21.3)\end{array}$ & $\begin{array}{l}20.04 \quad \pm \\
(16.1 \text { to24.03) }\end{array}$ & 9.5 & $\begin{array}{l}20.3 \pm 9.4 \\
(16.3 \text { to } 24.2)\end{array}$ & \multirow{2}{*}{0.001} \\
\hline $\begin{array}{l}\text { Control } \\
(\mathrm{n}=26)\end{array}$ & $\begin{array}{l}1.8 \pm 6.7 \\
(-0.9 \text { to } 4.5)\end{array}$ & $\begin{array}{l}4.9 \pm 8.8 \\
(1.3 \text { to } 8.5)\end{array}$ & & $\begin{array}{l}3.6 \pm 7.09 \\
(0.7 \text { to } 6.4)\end{array}$ & \\
\hline
\end{tabular}


The data presented in table 3 show that the average improvement of attitude score in the experimental group is significantly higher than the control group $(\mathrm{p}=0.001)$. This improvement is retained after 3 months of intervention.

Table 3: Difference in attitude scores among persons with BPAD

\begin{tabular}{|c|c|c|c|c|}
\hline \multirow[b]{2}{*}{ Group } & \multicolumn{3}{|l|}{ Attitude scores } & \multirow[b]{2}{*}{ p value } \\
\hline & $\begin{array}{l}\text { Post test1-pretest } \\
\text { Mean } \pm \text { SD } \\
(95 \% \text { CI })\end{array}$ & $\begin{array}{l}\text { Post test2-pretest } \\
\text { Mean } \pm \text { SD } \\
(95 \% \text { CI })\end{array}$ & $\begin{array}{l}\text { Post test3-pretest } \\
\text { Mean } \pm \text { SD } \\
(95 \% \text { CI })\end{array}$ & \\
\hline $\begin{array}{l}\text { Experimental } \\
(\mathrm{n}=24)\end{array}$ & $\begin{array}{l}11.1 \pm 10.2 \\
(6.8 \text { to } 15.4)\end{array}$ & $\begin{array}{l}10.4 \pm 8.7 \\
(6.7 \text { to } 14.03)\end{array}$ & $\begin{array}{l}13.2 \pm 9.2 \\
(9.3 \text { to } 17.1)\end{array}$ & \multirow{2}{*}{0.001} \\
\hline $\begin{array}{l}\text { Control } \\
(n=26)\end{array}$ & $\begin{array}{l}-0.8 \pm 11.4 \\
(-5.6 \text { to } 3.8)\end{array}$ & $\begin{array}{l}0.6 \pm 11.1 \\
(-3.9 \text { to5.1) }\end{array}$ & $\begin{array}{l}1.8 \pm 9.9 \\
(-2.1 \text { to } 5.7)\end{array}$ & \\
\hline
\end{tabular}

\section{Discussion}

\subsection{Effect of psycho educative intervention on adherence to treatment}

The present finding showed that, the psycho educative intervention does not produce any significant improvement in adherence to treatment $(\mathrm{p}=0.111)$. These findings contradict the study findings of Harvey and Peet 1991 by showing an improvement in the reported tablet compliance [10]. Agara and Onibi(2007) proved that the patients in group psycho education were consistently more compliant with scheduled clinic appointments than the usual care group $(\mathrm{P}=0.0009, \mathrm{df}=34)$ [11]. Eker and Harkin (2012) reported that the adherence rate of the patients in the intervention group increased from $40 \%$ to $86.7 \%$ [12]. The present study showed that the psycho educative intervention seems to be an efficacious intervention along with other modalities of treatment for persons with BPAD. Vieta (2005) reported that, as an adjunct to pharmacotherapy of bipolar disorder, psycho education is a promising management component that increases treatment adherence and quality of life for patients [13]. Control group also had an increased adherence percentage which may be due to the monitoring done by the investigator in terms of intake of medicines. Even though there was no significant different between two groups, all participants in the experimental group had $100 \%$ adherence. This showed that the psycho education can be incorporated in the routine clinical care.

\subsection{Effect of psycho educative intervention on knowledge and attitude}

The present findings demonstrate that, there is a significant increase in knowledge and attitude scores among the intervention group. The study by Bernhard et al (2006) in Germany illustrated a statistically significant improvement among patients on the sum scores of the German questionnaire after the cognitive psycho education intervention. $(\mathrm{p}=0.002)$ [14]. Similar results were also found in the study by Even et al (2010) where the knowledge increased after the program and maintained even after 24 months [15].Hence it can be concluded that, psycho educative intervention can improve the knowledge level and the retention of the knowledge may be due to the handbook which was given to the participants. It clearly confirms that the continuous reinforcements can retain the acquired knowledge and change the attitude of the patients.

\section{Conclusion}

The present study may have implications for the dissemination of effective psycho education in routine treatment of persons with Bipolar Affective Disorder. Continuous reinforcement and support of heath care team members can improve the adherence to treatment. The limitations of the study are multiple indicators were not used to assess the adherence to treatment and there was no control over the medication regimen prescribed by the consultant. The study can be replicated on a larger sample with more sessions and also a longer follow-up period.

\section{Acknowledgements}

Thank all the participants for their help and co-operation throughout the study. Authorities of the concerned institution for the permission to conduct the study.

\section{References}

[1] Akiskal, HS. Bourgeois, ML. Angst, J. Post, R. Moller, H. Hirschfeld, R. Re-evaluating the prevalence of and diagnostic composition within the broad clinical spectrum of bipolar disorders.

J Affect Disord, 59(suppl), 2000, S5-S30.

[2] Angst, J. Gamma, A. Benazzi, F. Adjacie, V. Eich, D. Rossler, W. Toward a re-definition of subthreshold bipolarity: epidemiology and proposed criteria for bipolar II, minor bipolar disordersand hypomania. J Affect Disord, 73, 2003, 133 - 146.

[3] Ganguli, H C. Epidemiological findings on prevalence of mental disorders in India.Indian J Psychiatry.42 (1),2000,14-20.

[4] Berk, KL. Hallam, KT. Colom, F. Vieta, E. Hasty, M. Macheil, C. etal.Enhancingmedicationadherence in patients with bipolar

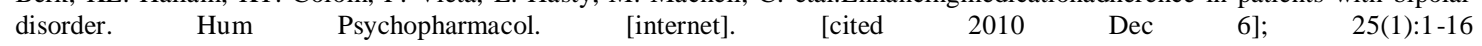
(Availablefrom:http://onlinelibrary.wiley.com/doi/10.1002/ hup.1081/abstract). 
[5] Centorrino, F. Hernan, MA .Ferrante, GD. Rendall, M. Apicella, A. Langar, G. Baldessarini, RJ. Factors Associated with Noncompliance with Psychiatric outpatient visits. Psychiatr Serv. 55(3)2001.378-380.

[6] Dawn, V. Pete,r W. Martha, S. Jan, S. Daniel, C. Ruth R et al. Assessment of adherence problems in patients with serious and persistent mental illness: Recommendation from expert consensus guidelines. J of PsychiatrPract [internet]. Jan 2010 [cited 2010 Sept 08]; 16(1): 34-35. ( Available from http://www.biomedsearch.com/nih/Assessment-adherence-problemsinpatients/20098229.html)

[7] Vieta E, Colom F. Psychological interventions in bipolar disorder: From wishful thinking to an evidence based approach. ActaPsychiatrScnd.110, 2004:.34 -38.

[8] Young, RC. Biggs, JT. Ziegler, VE. Meyer, DA. 1978. A rating scale for mania: reliability, validity and sensitivity. Br J Psy chiatry [internet]. [cited 2007 May 7]; 133:429-435. Available from: E:/HDRS\&YMRS 5 ${ }^{\text {th }}$ DEC 2007/Young Mania Rating Scale (YMRS).htm.

[9] Bagby, RM. Ryder, AG. Schuller, DR. Marshall, MB. The Hamilton Depression Rating Scale: Has the gold standard become a head weight? Am J Psychiatry, 161 (12), 2004, 2163 -2177.

[10] Harvey, NS. Peet, M. Effects of personality and attitude on health information acquisition and compliance.BJ Psych, 158(2), 1991, 200-204.

[11] Agara, AJ. Onibi, OE. 2007. Effects of group psycho-education on compliance with scheduled clinic appointments in a neuropsychiatric hospital in Southwest Nigeria: RCT. Ann Acad Med [internet]. [cited 2010 Oct 16]; 36 (4):272-276. Available from :http://www.ncbi.nlm. nih.gov/pubmed/17483857.

[12] Eker, F. Harkin S. Effectiveness of six week psychoeducation program on adherence of patients with bipolar affective disorder. J Affect Disord, 138 (3), 409-416.doi: 10.1016/j.jad.2012.01.004.

[13] Vieta, E. Improving treatment adherence in bipolar disorder through psycho education. J ClinPsychiatry.66(suppl 1), $2005,24-29$.

[14] Bernhard, B.Schaub, A. Kummler, P. Dittmann, S. Severus, E. Seemuller, F et al.Impact of cognitive -psycho-educational intervention in bipolar patients and their relatives. European Psychiatry [internet]. March 2006 [cited 2010 Oct 16]; 21(2): 81-86. Available from: http: www.ncbi.nlm.gov/pubmed/16380236.

[15] Even, C. Thuile, J. Kalck, M. Criquillion, S. Gorwood, P. Rouillon, F. Effect of psycho-education on lithium knowledge and attitude .J Affect Disord, 123(1-3), 2010, 299-302. 